\title{
Novel Recycle Technology for Recovering Gallium arsenide from
}

\section{scraped integrated circuits}

Lu Zhan ${ }^{\mathrm{a}, \mathrm{b}, \mathrm{c}}$, Yongliang Zhang ${ }^{\mathrm{b}}$, Zahoor Ahmad ${ }^{\mathrm{b}, \mathrm{d}}$, Zhenming Xu*,a,c

a School of Environmental Science and Engineering, Shanghai Jiao Tong University, 800 Dongchuan

$$
\text { Road, Shanghai 200240, China }
$$

b Shanghai Key Lab for Urban Ecological Processes and Eco-Restoration, School of Ecological and Environmental Science, East China Normal University, 500 Dongchuan Road, Shanghai 200241, China c Shanghai Institute of Pollution Control and Ecological Security, 1515 North Zhongshan Road,

$$
\text { Shanghai 200092, China }
$$

d Department of Soil Science, The University of Haripur, Haripur, Khyber Pakhtunkhwa, Pakistan

* Corresponding author: Prof. Zhenming Xu; phone: +86 21 54747495; fax: +86 21 54747495; email: $\underline{\text { zmxu@situ.edu.cn }}$

\section{Total number of Pages: 6}

\section{Total number of Figures: 1}

Total number of Tables: 4

Supporting materials are 6 pages in total, as follows.

Method of preparing phosphate buffer.

Method of digest before quantification on ICP-MS.

Table S2 The main instruments used in the experiment.

Table S3 Changes of $\mathrm{pH}$ before and after the experiment.

Table S4 Elemental composition of organic compounds.

FTIR analysis of organic compounds in packaging materials.

Figure S1 FTIR spectrogram of packaging materials. 


\section{Method of preparing phosphate buffer}

Chemical used: $\quad \mathrm{A}\left(\mathrm{NaH}_{2} \mathrm{PO}_{4} \cdot 2 \mathrm{H}_{2} \mathrm{O}\right)$ and $\mathrm{B}\left(\mathrm{Na}_{2} \mathrm{HPO}_{4} \cdot 12 \mathrm{H}_{2} \mathrm{O}\right)$

Preparation method: Firstly, a certain mass of A and B was weighed by electronic balance, and then they are mixed respectively with ultrapure water to prepare a certain concentration of $\mathrm{A}$ and $\mathrm{B}$ solution, and the concentration of $\mathrm{A}$ and $\mathrm{B}$ solution must be the same. Secondly, mixing A and B solutions in different proportions, a buffer solution of certain concentration with different $\mathrm{pH}$ values can be prepared. Thirdly, the $\mathrm{pH}$ value of the prepared buffer solution was measured by the $\mathrm{pH}$ meter (model $\mathrm{pH} 400$, Alais). If the $\mathrm{pH}$ value is lower than the required value, adding solution $\mathrm{B}$ to the prepared buffer solution by the burette. If the $\mathrm{pH}$ value is higher, solution $\mathrm{A}$ is added to the prepared buffer solution until the $\mathrm{pH}$ value is determined as the required value.

Example of preparation method: The preparation of phosphate buffer solution with concentration of $0.2 \mathrm{~mol} / 1$ and $\mathrm{pH}$ value of 7.4 was taken as an example.

(1) The preparation of $0.2 \mathrm{~mol} / 1$ solution A and solution B: $15.6 \mathrm{~g} \mathrm{~A}$ and $35.816 \mathrm{~g}$ B were weighed by electronic balance and dissolved in $500 \mathrm{ml}$ ultrapure water respectively. Solution A and solution B with concentration of $0.2 \mathrm{~mol} / 1$ were prepared.

(2) Taking $10 \mathrm{ml}$ A solution in $200 \mathrm{ml}$ beaker, then add B solution in beaker with burette, and constantly test the $\mathrm{pH}$ value of the mixed solution. When the $\mathrm{pH}$ value approaches 7.4, slow down the adding speed of B solution until the final $\mathrm{pH}$ value of mixed solution is 7.4 .

(3) Further check the $\mathrm{pH}$ value of the solution after 1 minute, if the $\mathrm{pH}$ value is greater than 7.4 , then slowly add solution $\mathrm{A}$, if the $\mathrm{pH}$ value is less than 7.4 , then slowly add solution $\mathrm{B}$ until the $\mathrm{pH}$ value is stable at 7.4.

(4) When the $\mathrm{pH}$ value was stable at 7.4, we found that the volume of solution A and solution B was $10 \mathrm{ml}$ and $42.6 \mathrm{ml}$, respectively.

Thus a phosphate buffer solution with a concentration of 0.2 and a $\mathrm{pH}$ value of 7.4 can be prepared. So, buffers with different concentrations and $\mathrm{pH}$ can be prepared by changing the concentration and proportion of A and B solutions. 


\section{Method of digest before quantification on ICP-MS}

We used the standards issued by the Ministry of Ecology and Environment of the People's Republic of China to test the materials. The standard name is Solid WasteDetermination of metals - Inductively Coupled Plasma Mass Spectrometry and the number is $H J 766-2015$ and we have adjusted and optimized the heating program of microwave digestion instrument. After adjusting the heating program, first, we detected the standard gallium and arsenic after digestion, and the error was less than 1\%, which confirmed the validity of the data. The general process is as follows:

After hydrothermal treatment, we use microwave digestion method to digest solid residues and hydrothermal solution. The microwave digestion instrument was purchased from XTustInstruments Company, model XT-9916. The heating procedure of microwave digestion apparatus is shown in Table S1.

Table S1 The heating procedure of microwave digestion.

\begin{tabular}{ccc}
\hline heating time $(\mathrm{min})$ & digestion temperature $\left({ }^{\circ} \mathrm{C}\right)$ & holding time $(\mathrm{min})$ \\
\hline 10 & $\sim 120$ & 6 \\
5 & $120 \sim 160$ & 6 \\
5 & $160 \sim 180$ & 40 \\
\hline
\end{tabular}

After microwave digestion and acid removal, we transfer the remaining digestion solutions to the volumetric flask for constant volume. Then the treated samples be tested by ICP-MS.

Table S2 The main instruments used in the experiment.

\begin{tabular}{ccccc}
\hline & instrument & model & producer & geographical place \\
\hline 1 & ICP-MS & ICP-MS-7800 & Agilent & USA \\
2 & XPS & AXIS Ultra DLD & Shimadzu & Japan \\
\hline
\end{tabular}




\begin{tabular}{ccccc}
\hline 3 & XRD & LabX XRD-6100 & Shimadzu & Japan \\
4 & GC-MS & GCMS-QP2010 & Shimadzu & Japan \\
5 & SEM-EDS & Sirion 200 & FEI, United States & USA \\
\hline
\end{tabular}

Table S3 Changes of $\mathrm{pH}$ before and after the experiment.

\begin{tabular}{|c|c|c|c|c|c|}
\hline \multicolumn{6}{|c|}{ Hydrothermal Treatment with Buffering Solution } \\
\hline Before the experiment $\mathrm{pH}$ & 7.4 & 7.6 & 7.8 & 8.0 & 8.2 \\
\hline After the experiment $\mathrm{pH}$ & 5.88 & 5.91 & 6.05 & 6.13 & 6.41 \\
\hline Experiment condition & $\begin{array}{l}275^{\circ} \mathrm{C} \\
\text { buffer c }\end{array}$ & $/ \mathrm{min}$, & $\begin{array}{l}\mathrm{ng} \mathrm{5 \%} \\
001 \mathrm{mc} \\
\sim 8.2\end{array}$ & uffer & $\begin{array}{l}\mathrm{fH}_{2} \mathrm{O}_{2} \\
\mathrm{pH} 7.4\end{array}$ \\
\hline
\end{tabular}

Table S4 Elemental composition of organic compounds.

\begin{tabular}{llllllll}
\hline Element & $\mathrm{Si}$ & $\mathrm{O}$ & $\mathrm{C}$ & $\mathrm{H}$ & $\mathrm{Br}$ & $\mathrm{N}$ & $\mathrm{P}$ \\
Content (wt. \%) & 45.34 & 36.25 & 14.47 & 2.561 & 0.41 & 0.26 & 0.13 \\
Element & $\mathrm{Ca}$ & $\mathrm{Al}$ & $\mathrm{Na}$ & $\mathrm{Fe}$ & $\mathrm{Sn}$ & & \\
Content (wt. \%) & 0.02 & 0.02 & 0.02 & 0.01 & 0.01 & & \\
\hline
\end{tabular}

\section{FTIR analysis of organic compounds}

As shown in Figure S1, the most intense peak is at $1104 \mathrm{~cm}^{-1}$ which can be attributed to asymmetric Si-O-Si stretching vibration. The strong absorptions at $471 \mathrm{~cm}^{-1}$ and 804 $\mathrm{cm}^{-1}$ are associated with symmetric stretching vibration and asymmetric bending vibration of $\mathrm{Si}-\mathrm{O}-\mathrm{Si}$ respectively, which indicates that $\mathrm{SiO}_{2}$ is present as inorganic filler of packaging materials. ${ }^{1}$ FTIR spectrum also shows aromatic $\mathrm{C}=\mathrm{C}$ stretches at 1452 , 1508 and $1606 \mathrm{~cm}^{-1}$, symmetric stretching vibration of methyl groups at $2870 \mathrm{~cm}^{-1}$ and asymmetric stretching vibration of methylene groups at $2920 \mathrm{~cm}^{-1}$. The peak at 3465 $\mathrm{cm}^{-1}$ may represent $\mathrm{O}-\mathrm{H}$ stretches in phenols without forming hydrogen bonds. 
However, the spectral region closes to the epoxide C-O-C vibration $\left(908 \mathrm{~cm}^{-1}\right)$ shows no peaks, indicating that the organic compounds (Phenolic resin and epoxy resin) in packaging materials were fully cured. ${ }^{2}$

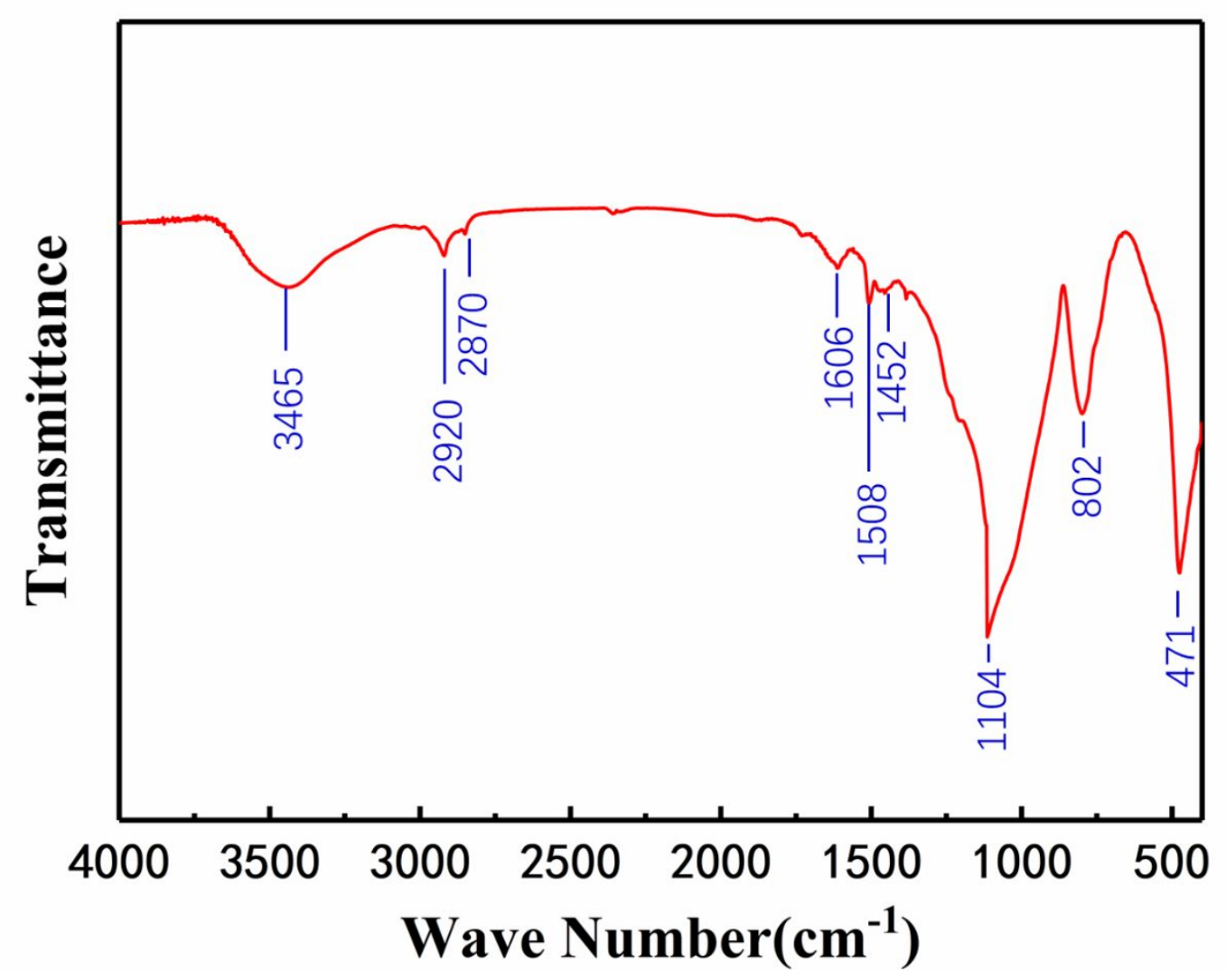

Figure S1 FTIR spectrogram of organic compounds.

\section{References}

(1) PISCIELLA; Paola; PELINO; etc. FTIR spectroscopy investigation of the crystallisation process in an iron rich glass. J. Eur. Ceram. Soc. 2005, 25 (11), 1855 1861.

(2) Alam, M. A.; Das, D.; Azarian, M. H.; etc. Influence of Molding Compound on Leakage Current in MOS Transistors. IEEE Transactions on Components Packaging \& Manufacturing Technology 2011, 1 (7), 1054-1063. 